\title{
HYDROGEN EMBRITTLEMENT OF COLD DRAWN PRESTRESSING STEELS: THE ROLE OF THE DIE INLET ANGLE
}

\author{
J. TORIBIO, M. LORENZO, D. VERGARA, V. KHARIN \\ University of Salamanca, Campus Viriato, Zamora, Spain
}

Cold-drawn prestressing steel wires are susceptible to hydrogen embrittlement (HE) in aggressive environments, and residual stress-strain states generated in wires by the drawing process play the key role there. Correspondingly, alterations of the stress-strain fields due to peculiarities of the drawing procedure affect the serviceability of wires under HE. On the basis of performed numerical simulations of the process of cold drawing with the use of different drawing dies, the paper addresses the effect of the inlet angle of the die on residual stress-strain fields in wires, and derives their consequences for wires hydrogenation and their susceptibility to HE. The reduction of the die inlet angle is shown to be beneficial for the wires performance.

Keywords: prestressing steel, cold drawing, die design, residual-strain state, hydrogen diffusion.

Prestressing steel wires, widely used in civil engineering to reinforce concrete structures, are obtained by cold drawing of pearlitic steel. The process consists of a progressive reduction of the cross sectional area of hot rolled steel bars forced to pass through a succession of rigid dies. Plastic strains generated in steel during drawing are non-uniform along the wire diameter, which raises residual stresses there [1-3]. The drawing-induced stresses are not negligible [1-4], and they usually have substantial influence on the wires performance under applied tensile load $[5,6]$. The relevancy of these residual stresses to wire strength and fatigue life in service has been well documented $[2,5,6]$. In addition, crucial role is attributed to drawing-induced residual stresses in environment-assisted fracture of prestressing steels via hydrogen embrittlement (HE) mechanism [3, 6, 7]. In this case, the main mode of hydrogen transport towards microstructural fracture sites, which is considered to be hydrogen diffusion in metal, depends strongly on both hydrostatic stress and accumulated plastic strain [3, 7-10], which turns them out to be the key factors of hydrogen supply to critical regions in wires.

Dependence of residual stresses and strains in cold-drawn wires on the drawing process parameters [4], such as the geometry of dies in use, substantiates the interest to analyse the effects that certain manufacturing conditions could have on wires fracture in harsh environments. In particular, the aim of this work consists in evaluation of the residual stress-strain states generated by distinct drawing processes using the dies with various inlet angles, and to infer about their consequences for hydrogen behaviour in the drawn wires to foresee the influence of die inlet angle on the susceptibility of prestressing steels to HE.

Modelling. One-step cold drawing processes were simulated, in which distinct dies were employed having different inlet angles corresponding to the range of values commonly used in cold drawing industry [11]: small die inlet angle $\alpha=5^{\circ}$, intermediate $\alpha=7^{\circ}$, and large $\alpha=9^{\circ}$. All the dies provided the same reduction of wire diameter

Corresponding author: J. TORIBIO, e-mail: toribio@usal.es 
from the initial diameter $d_{0}=12 \mathrm{~mm}$ to the final one $d_{1}=10.8 \mathrm{~mm}$ (Fig. 1). The behaviour of the steel during drawing was represented by the constitutive model of elastoplastic material with the von Mises yield surface and associated flow rule that obeyed isotropic hardening according to the equivalent stress $\bar{\sigma}-$ equivalent strain $\bar{\varepsilon}$ mastercurve (Fig. 2), which was obtained from the ordinary tensile test data [12]. According to the cited data, the Young modulus of 197.4 MPa and Poisson coefficient of 0.3 were used in simulations for steel. To provide desired performance of dies, i.e., their dimensional stability and strength, they are usually made of hard materials that operate during drawing process in the elastic regime, such as tungsten carbide that has the Young modulus $600 \mathrm{GPa}$ and ultimate tensile strength (UTS) of $5000 \mathrm{MPa}$ and Poisson coefficient of 0.27 . Then, the die was considered in simulations as elastic body with the mentioned mechanical characteristics.

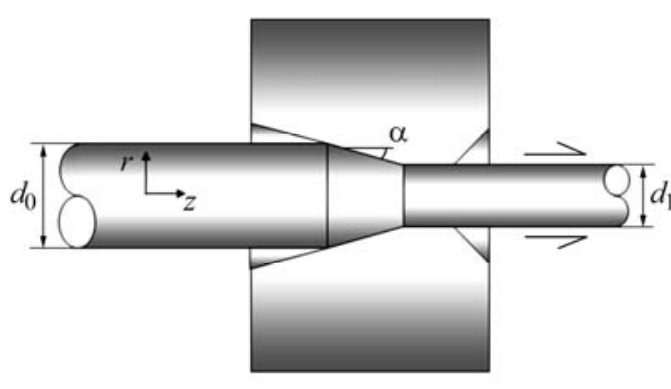

Fig. 1.

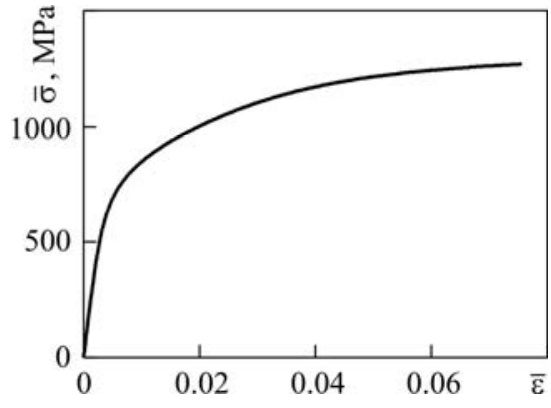

Fig. 2.

Fig. 1. Scheme of the one step cold drawing process.

Fig. 2. Experimental stress-strain mastercurve of the steel [12].

To analyse the effect of drawing procedure on HE susceptibility of prestressing steels, hydrogen supply to prospective critical sites in wires can be assessed through the steady-state hydrogen distributions in metal provided by diffusion. This latter is assisted by both stress and plastic strain, as described in detail elsewhere [3, 7, 9]. In brief, the stress-strain assisted hydrogen diffusion in metals is described by hydrogen flux $J$ dependent on the hydrostatic stress $\sigma$, as well as on the equivalent plastic strain $\bar{\varepsilon}_{\mathrm{P}}$ that represents the variation of the amount of microstructural defects - hydrogen traps - in plastically deformed metal [13]. Traps affect the plastic-strain dependent component of hydrogen solubility $K_{\mathrm{S} \varepsilon}=K_{\mathrm{S} \varepsilon}\left(\bar{\varepsilon}_{\mathrm{P}}\right)$ and the hydrogen diffusivity $D=D\left(\bar{\varepsilon}_{\mathrm{P}}\right)$ in metal $[13,14]$, which renders the diffusion flux as follows [15]:

$$
\mathbf{J}=-D\left(\bar{\varepsilon}_{\mathrm{P}}\right)\left\{\nabla C-C\left[\frac{V_{\mathrm{H}}}{R T} \nabla \sigma+\frac{\nabla K_{\mathrm{S} \varepsilon}\left(\bar{\varepsilon}_{\mathrm{P}}\right)}{K_{\mathrm{S} \varepsilon}\left(\bar{\varepsilon}_{\mathrm{P}}\right)}\right]\right\},
$$

where $R$ is the universal gas constant, $V_{\mathrm{H}}$ is the partial molar volume of hydrogen in metal and $T$ is the absolute temperature. Due to the effect of trapping [14], hydrogen solubility in metals is usually rising function of the accumulated plastic strain $\bar{\varepsilon}_{\mathrm{P}}$, so that for the steel under consideration at ambient temperature a linear fit can be adopted as follows $[3,9]$ :

$$
K_{\mathrm{S} \varepsilon}\left(\bar{\varepsilon}_{\mathrm{P}}\right)=1+4 \bar{\varepsilon}_{\mathrm{P}} .
$$

During hydrogenation of a metal piece immersed in a given charging environment, the steady state hydrogenation of metal is finally attained at long diffusion times. This can be considered as the approaching of thermodynamic equilibrium among the states of hydrogen within and upon the surface of metal, and it can be related to the 
input fugacity (thermodynamic activity) of hydrogen produced by a given charging system at its operative parameters [16]. This thermodynamic activity can be characterised in terms of the equilibrium hydrogen concentration $C_{0}$ in a stress-strain free metal under given harsh environment $[3,9]$. Then, corresponding steady-state solution of the equation of the stress-strain assisted hydrogen diffusion at fixed thermodynamic activity of the incoming hydrogen is given by the equilibrium hydrogen distribution in metal, as follows [3]:

$$
C_{\mathrm{eq}}=C_{0} K_{\mathrm{S} \varepsilon}\left(\bar{\varepsilon}_{\mathrm{P}}\right) \exp \left[\frac{V_{\mathrm{H}}}{R T} \nabla \sigma\right] .
$$

This equilibrium concentration $C_{\text {eq }}$ provides the utmost limit of hydrogenation that can be ever attained in a stressed-strained metal immersed in given hydrogenating environment.

Due to cylindrical symmetry of the wire and the dies, the axisymmetric formulation of the problem of evaluation of the stress-strain state and hydrogenation of the cold-drawn wires is appropriate. The simulations of the drawing process as a contact problem between elastoplastic bar and elastic die were performed using the generalpurpose nonlinear finite-element code within updated lagrangian large displacementfinite strain formulation. Diverse finite element meshes were tried to ensure the meshconvergence of the solution. The details of the numerical modelling were presented in details elsewhere [3].

Results. The results presented herein focus on the mechanical variables that affect hydrogen diffusion in cold-drawn wires according to the adopted model, cf. equations (1)-(3), i.e. on the drawing-induced hydrostatic stress $\sigma$ and equivalent plastic strain $\overline{\mathcal{E}}_{\mathrm{P}}$. In addition, since the fracture behaviour of the prestressing wires is determined by the superposition of the axial applied load and the drawing-induced residual stress $\sigma_{z}$, this latter is addressed as well to identify the potentially critical zones, where hydrogen assisted fracture could start.

Accordingly, for the three analysed cold drawing processes, Fig. 3 shows the distributions of equivalent plastic strain, and Fig. 4 displays the distributions of hydrostatic and axial stresses in wires along the radial coordinate $\mathrm{r}$.

Fig. 3. Distributions of the equivalent plastic strain generated by three cold drawing processes with different values of the die inlet angle $\alpha$ :

$\diamond-\alpha=5^{\circ} ; \bigcirc-\alpha=7^{\circ} ; \square-\alpha=9^{\circ}$.

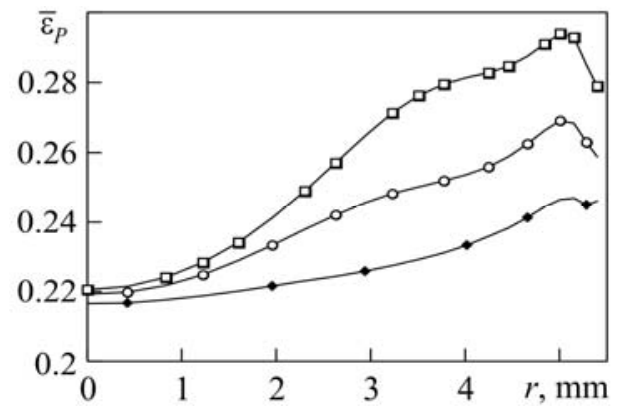

As it can be noticed in Fig. 3, equivalent plastic strain $\bar{\varepsilon}_{\mathrm{P}}$ produced by drawing is sensible to variation of the die inlet angle $\alpha$. This influence is observed throughout the whole wire section with the exception of the wire axis at $r=0$, where the difference is rather insignificant. This way, wire drawing with smaller die inlet angle generates lower plastic strain peaks, i.e., provides its more uniform distribution along the wire radius. As the inlet angle increases, the equivalent plastic strain rises towards higher values at the wire periphery, and so, it becomes less homogeneous. The effect is particularly noticeable near the wire surface at $3.8<r \leq 5.4 \mathrm{~mm}$, where larger differences of the plastic strain are achieved. In addition, significant elevation of the in-coming (i.e., 
directed towards the wire interior) gradient of the equivalent plastic strain is observed at $4.9<r \leq 5.4 \mathrm{~mm}$. This is especially relevant to the hydrogen diffusion process because the gradient of hydrogen solubility is directly related to $\nabla \bar{\varepsilon}_{\mathrm{P}}$, i.e., $\nabla K \mathrm{~S} \varepsilon \sim \nabla \bar{\varepsilon}_{\mathrm{P}}$, and so, this driving factor of hydrogen diffusion moves hydrogen there into the wire according to equations (1) and (2).
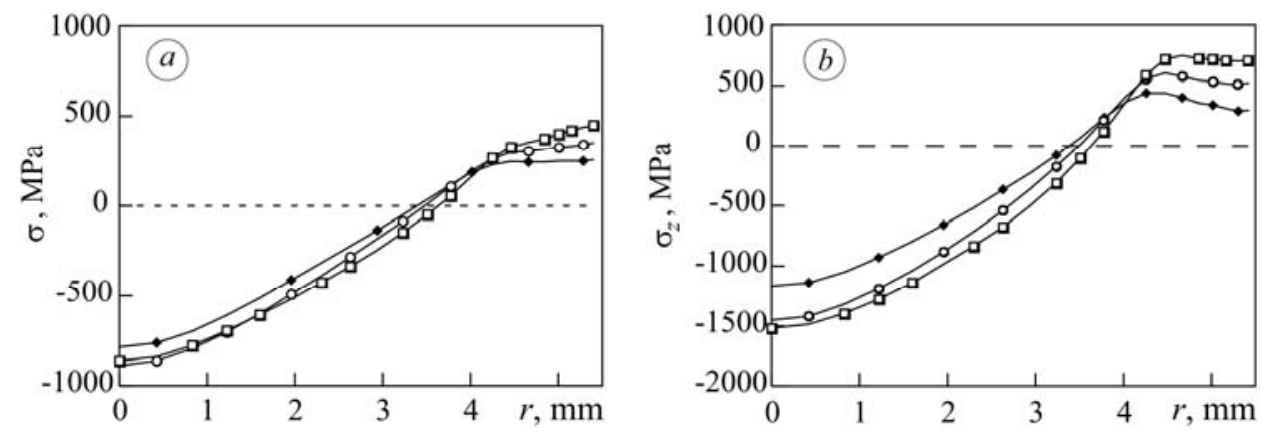

Fig. 4. Distributions of the hydrostatic $(a)$ and axial $(b)$ stresses generated by three cold drawing processes with different values of the die inlet angle $\alpha$ : $-\alpha=5^{\circ} ; \bigcirc-\alpha=7^{\circ} ; \square-\alpha=9^{\circ}$.

With regard to the distributions of residual hydrostatic and axial stresses (Fig. 4), the same trend of the stress increase from the wire axis to its periphery is observed for all studied drawing processes. In agreement with other experimental measurements and modelling data $[1-4,6,7]$, elevated tensile residual stresses arise near the wire surface, being compensated by compressive ones in the interior closer to the wire axis. Similarly to what was observed for plastic strain distributions (Fig. 3), the lower stress extremes and more uniform stress distributions are obtained in the wires drawn with smaller values of the die inlet angle $\alpha$. Respectively, as $\alpha$ increases, both hydrostatic and axial stresses attain the higher peak values and their distributions become less homogeneous. Major differences of the drawing-induced stresses are observed in the proximity of wire surface at about $4.3<r \leq 5.4 \mathrm{~mm}$, where the maximum plastic strain values are attained, too (cf. Fig. 3). However, in the matter of the hydrostatic stress gradient $\nabla \sigma$, which appears among the driving forces of the stress-strain assisted diffusion in equation (1), it turns out to have the overall out-going direction, i.e., towards the wire exterior (Fig. 4a), which must slow down the hydrogenation of wires in aggressive environments. Though, the effect of the die inlet angle on $\nabla \sigma$ is fairly negligible in the wire interior approximately at $r<4.3 \mathrm{~mm}$, neither stress gradients associated with different inlet angles look remarkable in the near-surface domain $r>4.3 \mathrm{~mm}$.

Finally, substantial elevation of the axial residual stress $\sigma_{z}$ towards the wire periphery (Fig. $4 b$ ), which agrees with other available results of measurements and modelling $[1-4,6]$, points out the region $4.3<r \leq 5.4 \mathrm{~mm}$ as the one that is determinative for wires strength and fracture in general, and under HE in particular. With regard to the effect of the die inlet angle on the axial residual stress in wires, the higher values of the peak tensile stress in this potential fracture process zone near the wire surface are generated with dies that have larger $\alpha$.

Discussion. Generated stress-strain results allow the qualitative assessment of the effects of drawing process parameters on wire hydrogenation, and accordingly, on HE susceptibility of cold drawn steel wires. Presented results manifest that alterations of the distributions of residual stresses and plastic strain, which are attributable to the difference of the employed dies, are localised mainly near the wire surface at about $3.8<r \leq 5.4 \mathrm{~mm}$ with minor perturbations in the wire interior. Within the framework 
of the adopted hydrogen diffusion model (1), the gradients of hydrostatic stress and equivalent plastic strain appear as additional driving forces of hydrogenation, which accompany the classical one related to the sole gradient of concentration [17]. Taking into account that the mechanical variables, such as $\bar{\varepsilon}_{\mathrm{P}}$ and $\alpha$, which govern the wire hydrogenation, as well as $\sigma_{z}$, which controls the wire fracture, manifest the main differences in the near-surface domain (Figs. 3 and 4), it seems to be pertinent to focus on this zone.

In the matter of the drawing-induced plastic strain that may be considered as the indication of the population of hydrogen traps in steels, its role consists in overall increase of hydrogen absorption capacity of steel, i.e., it favours wire hydrogenation according to equations (2) and (3). In addition, by virtue of equation (1), the in-going gradient of plastic strain in the wire periphery $4.9<r \leq 5.4 \mathrm{~mm}$ enhances there the hydrogen in-come flux towards the wire interior from the metal surface, where hydrogen provided by the environment enters into the metal. This way, plastic strain distributions cause both elevation of the attainable hydrogen content and acceleration of the hydrogen accumulation in the most stressed region in the wire, where hydrogen-assisted fracture initiation then must be expected.

Concerning the magnitude of the die inlet angle, increase of $\alpha$ from 5 to $9^{\circ}$ raises both the plastic strain magnitude (up to approximately $20 \%$ ) and the in-going plastic strain gradient (up to about 90\%) in the wire periphery $4.9<r \leq 5.4 \mathrm{~mm}$. This implies there, correspondingly, increase of hydrogen solubility and rising of one of the driving forces of in-coming diffusion that is associated with the gradient of strain-affected hydrogen solubility, i.e., with $\nabla K_{s \varepsilon}\left(\bar{\varepsilon}_{\mathrm{P}}\right)$, cf. equations (1)-(3). Accordingly, this draws two consequences, which both favour the HE of cold-drawn wires: augmentation of the attainable level of metal hydrogenation under the same environmental conditions by virtue of equation (3) and acceleration of the wire hydrogenation by virtue of equation (1), which both take place in the zone of the highest axial tensile stresses in the cold drawn wires.

However, apart from the effect on solubility, hydrogen trapping in metals has also consequences for its mobility $[18,19]$ in the way that hydrogen diffusivity $D$ is reduced by trapping, which is reflected by the declining dependence $D=D\left(\bar{\varepsilon}_{\mathrm{P}}\right)[3,7,9,18,20]$. This way, although drawing-induced plastic strain raises the hydrogen absorption capacity of cold-drawn steel (i.e., the attainable level of its hydrogenation under given environmental conditions) and, in addition to that, its in-ward gradient accelerates hydrogen delivery to potentially critical regions, thereby facilitating HE of wires, but the effect of strain on diffusivity slows down wire hydrogenation, and thus postpones HE.

In due course, the influence of the die inlet angle $\alpha$ on drawing-induced residual hydrostatic stress implies two competing consequences for the wire hydrogenation, too. First, appreciable in Fig. $4 a$ at $r>4.3 \mathrm{~mm}$ elevation of the magnitude of out-going (i.e., towards the wire surface) gradient of hydrostatic stress when the angle $\alpha$ increases means rising of another of the driving forces of hydrogen diffusion, which is associated with $\nabla \sigma$, cf. equation (1). Being out-wards directed, this latter slows down the in-ward hydrogen diffusion from the metal surface according to equation (1), and this counteraction to hydrogenation flux is higher when the die angle $\alpha$ is greater. However, the attainable magnitudes of $\nabla \sigma$ in the near-surface region $4.3<\mathrm{r} \leq 5.4 \mathrm{~mm}$ in wires (Fig. $4 a$ ) are rather moderate, if not negligible, so that this factor is expected to have minor importance for wire hydrogenation rate. Second, increase with the angle $\alpha$ of the residual hydrostatic stress magnitude near the surface implies rising of the amount of hydrogen that can be absorbed there in agreement with equation (3), i.e., this renders hydrogenation enhancement. In the present case, the stress-related augmentation of 
hydrogen absorption by metal, which owes to the increase of die inlet angle from $5^{\circ}$ to $9^{\circ}$, attains up to about $18 \%$ according to equation (3) with usual for steels value of $V_{\mathrm{H}}=2 \mathrm{~cm}^{3} / \mathrm{mol}[14]$ and $T=323 \mathrm{~K}$. This is more significant than that associated with the contribution of plastic strain elevation with increase of $\alpha$, which attains some $7 \%$. Anyhow, concerning potential fracture process zone near the wire surface, the consequences for $\mathrm{HE}$ of residual stresses generated with larger values of the die inlet angle $\alpha$ are there twofold: the delay (apparently, minor if any) of hydrogenation in time due to the opposition of the hydrostatic stress gradient to the diffusion flux by virtue of equation (1), and the elevation of hydrogenation in the magnitude due to the stress induced increase of hydrogen absorption expressed by equation (3).

To visualize the foresights about hydrogen accumulation in cold drawn wires, Fig. 5 displays hydrogen distributions in wires in equilibrium with the thermodynamic activity of incoming hydrogen according to expression (3) with $V_{\mathrm{H}}=2 \mathrm{~cm}^{3} / \mathrm{mol}$ [14] and $T=323 \mathrm{~K}$ under the drawing-induced stress-strain fields revealed by performed modelling, which are presented in Figs. 3 and $4 a$. These $C_{\text {eq }}$ values give the upper bounds of hydrogenation attainable under given environmental conditions in the wires in definite locations $r$ after respective cold-drawing procedures, and thus, they provide an insight about the utmost expectable hydrogen harm in prestressing steels. To this end, the main differences between hydrogen distributions in the wires drawn with different dies are located close to the wire surface at $3.5<r \leq 5.4 \mathrm{~mm}$ (Fig. 5) in the same manner as it has been pointed out for the distributions of hydrostatic stress and plastic strain (Figs. 3 and $4 a$ ). Elevation of both them near the wire surface implies the increase of attainable amount of hydrogen there from about $10 \%$ for $\alpha=7^{\circ}$ to about $25 \%$ for $\alpha=9^{\circ}$ if compared with hydrogenation level attainable in wires drawn with the die having $\alpha=5^{\circ}$. This way, the amount of hydrogen that can be accumulated in the highly stressed and strained near-surface zone in wires at $4.3<r \leq 5.4 \mathrm{~mm}$ increases with the die inlet angle (Fig. 5). As well, the axial tensile residual stress $\sigma_{z}$ in wire, which is responsible for fracture [3, 5-7], does the same (Fig. 4b). Correspondingly, the potential damage associated with HE must be more detrimental in the wires drawn with greater die inlet angles. Therefore, according to the presented results, the larger angle of dies used in drawing makes prestressing steel wires potentially more susceptible to HE and premature fracture.

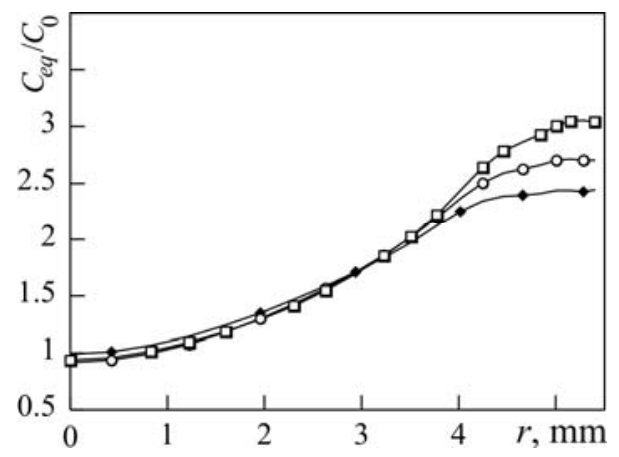

Fig. 5. Distributions of the ultimate hydrogen concentration in wires under stress-strain states generated by three cold drawing processes with different values of the die inlet angle $\alpha$ : $-\alpha=5^{\circ} ; \bigcirc-\alpha=7^{\circ}$; $-\alpha=9^{\circ}$.

\section{CONCLUSIONS}

Obtained results show that the inlet angle of dies employed in the manufacturing of cold-drawn wires is an important parameter of the drawing process from the point of view of the wires susceptibility to hydrogen embrittlement (HE) in service, as well as of their overall performance. The relevance of this parameter roots in that rather small alteration of the die inlet angle causes substantial change of the residual stress-strain 
state in wires, which, consequently, affects hydrogen accumulation in wires and their hydrogen assisted damage in service.

For the drawing-induced residual stresses and strains in wires, the main differences associated with the die inlet angles are localized in the near surface zone, which is responsible for fracture initiation both for merely mechanical and hydrogen related reasons. Smaller die inlet angles render lower levels of the near surface tensile residual stresses and accumulated plastic strain. Consequently, increase of the die inlet angle raises the peak axial stress, as well as both the rate and the magnitude of wire hydrogenation in harsh environments, which are attributable to the stresses and strains owing to their role in hydrogen behaviour in metals. On the other hand, this must delay somewhat the rate of hydrogenation associated with the strain-induced reduction of hydrogen diffusivity and stress-gradient associated component of hydrogen diffusion driving force, which, however, is rather vague. This way, the resistance of prestressing steel wires to HE in service is expected to get better with the use in the drawing process of the dies having reduced inlet angles.

РЕЗЮМЕ. Встановлено, що холоднодеформовані сталеві дроти для арматури попередньо напружених залізобетонів чутливі до водневого окрихчення (BО) в агресивних середовищах. Залишкові напружено-деформовані стани, які утворюються в цих дротах внаслідок холодного волочіння, відіграють при цьому ключову роль. Зміна цих напружено-деформованих станів через особливості процесу волочіння впливає на роботоздатність дротів під час ВО. На основі числового моделювання холодного волочіння з використанням відмінних фільєрів розглянуто дію вхідного кута фільєра на напружено-деформовані стани в дротах і зроблено висновки про наслідки їх впливів на наводнення дротів в агресивному середовищі і схильність до ВО. Показано, що зменшення вхідного кута фільєра волочіння має позитивний вплив на роботоздатність дротів.

РЕЗЮМЕ. Установлено, что холоднодеформированные стальные проволоки для арматуры предварительно напряженных железобетонов являются чувствительными к водородному охрупчиванию (ВО) в агрессивных средах. Остаточные напряженно-деформированные состояния, которые создаются в этих проволоках вследствие холодного волочения, играют при этом ключевую роль. Изменение этих напряженно-деформированных состояний вследствие особенностей процесса волочения влияет на работоспособность проволок при ВО. На основе численного моделирования холодного волочения с использованием различных фильеров рассмотрено воздействие входного угла фильера на напряженно-деформированые состояния в проволоках и сделаны выводы относительно последствий их влияния на наводороживание проволок в агрессивной среде и склонность к ВО. Показано, что уменьшение входного угла фильера волочения имеет положительное влияние на работоспособность проволок.

Acknowledgements. The authors wish to acknowledge the financial support provided by the following Spanish Institutions: Ministry for Science and Technology (Grant MAT2002-01831), Ministry for Education and Science (Grant BIA2005-08965), Ministry for Science and Innovation (Grants BIA2008-06810 and BIA2011-27870), Junta de Castilla y León (Grants SA067A05, SA111A07 and SA039A08).

1. Effect of lubrication during wire drawing on residual stresses in a cable wire / Z. I. Kostina, V. D. Chistota, G. E. Arkulis et al. // Materials Science. - 1974. - 10, № 3. - P. 75-76.

2. Atienza J. M., Ruiz-Hervias J., Martinez-Perez M. L., et al. Residual stresses in cold drawn pearlitic rods / // Scripta Materialia. - 2005. - 52. - P. 1223-1228.

3. Role of drawing-induced residual stresses and strains in the hydrogen embrittlement susceptibility of prestressing steels / J. Toribio, V. Kharin, M. Lorenzo, D. Vergara // Corrosion Science. - 2011. - 53. - P. 3346-3355.

4. Överstam $H$. The influence of bearing geometry on the residual stress state in cold drawn wire analysed by the FEM // Materials Processing Technol. - 2004 - 171. - P. 446-450. 
5. Effects of post-drawing treatments on the fatigue strength of eutectoid steel wires / K. Katagiri, T. Sato, K. Kasaba et al. // Fatigue Fract. Engng Materials and Structures. - 1999. - 22. - P. 753-760.

6. Elices $M$. Influence of residual stresses in the performance of cold-drawn pearlitic wires // J. of Materials Science - 2004. - 39. - P. 3889-3899.

7. Toribio J. and Elices $M$. Influence of residual stresses on hydrogen embrittlement susceptibility of prestressing steels // Int. J. of Solids and Structures. - 1991. - 28, № 6. - P. 791-803.

8. Andreikiv O. E. Mathematical modelling of hydrogen-assisted fracture in metals // Materials Science. -1997. - 33, № 4. - P. 450-464.

9. Two-dimensional numerical modelling of hydrogen diffusion in metals assisted by both stress and strain / J. Toribio, V. Kharin, D. Vergara, M. Lorenzo // Advanced Materials Research. - 2010. - 138. - P. 117-126.

10. Optimization of the simulation of stress-assisted hydrogen difussion for studies of hydrogen embrittlement of notched bars / J. Toribio, V. Kharin, D. Vergara, M. Lorenzo // Materials Science. - 2010. - 46, № 6. - P. 819-833.

11. ASM Handbook vol. 14: Forming and forging. - Materials Park: ASM International, 1988. $-2110 \mathrm{p}$.

12. Quantitative fractographic analysis of the fracture behaviour of progressively drawn pearlitic steels / F. J. Ayaso, B. González, J. C. Matos et al. // $10^{\text {th }}$ Portuguese Conf. on Fracture. - Guimaraes, 2006. - 10 p.

13. Dietzel W., Pfuff M., and Juilfs G. G. Hydrogen permeation in plastically deformed steel membranes // Materials Science. - 2006. - 42, № 1. - P. 78-84.

14. Hirth J. P. Effects of hydrogen on the properties of iron and steel // Metallurgical Transactions. -2005 . - 52. - P. 1223-1228.

15. Kronshtal $O$. and Kharin $V$. Influence of material inhomogeneity and variation of temperature on hydrogen diffusion as a risk factor of enhancement of metals hydrogen degradation // Soviet Materials Science. - 1992. - 28, № 6. - P. 475-486.

16. Oriani R. A. The Physical and Metallurgical Aspects of Hydrogen in Metals // ICCF-4, Fourth Int. Conf. on Cold Fusion. - Lahaina, Maui: Electric Power Research Institute, 1993. - 42 p.

17. Shewmon P. Diffusion in solids. - Minerals, Metals, and Materials Society, 1989. - 246 p.

18. Lunarska E. and Nikiforov $K$. Effect of prestraining on the behavior of hydrogen in structural steel // Materials Science. -2007. - 43, № 5. - P. 667-674.

19. Pavlyna V. S. and Pavlyna O. V. Hydrogen permeability in metals under the conditions of accumulation of defects // Materials Science. - 2007. - 43, № 5. - P. 597-607.

20. Influence of residual stress and strains generated by cold drawing on hydrogen embrittlement of prestressing steels / J. Toribio, V. Kharin, D. Vergara et al. // Corrosion Science. - 2007. - 49. - P. 3557-3569. 